\title{
Raman and Infrared Spectroscopy Studies of Carbon Nitride Films Prepared on Si (100) Substrates by Ion Beam Assisted Deposition
}

\author{
Wilmer Sucasaire, ${ }^{*, a}$ Masao Matsuoka, ${ }^{a}$ Karina C. Lopes, ${ }^{a}$ Juan C. R. Mittani, ${ }^{a}$ Luis H. Avanci, ${ }^{a}$ \\ Jose F. D. Chubaci, ${ }^{a}$ Nemitala Added, ${ }^{a}$ Vladimir Trava ${ }^{b}$ and Evaldo J. Corat ${ }^{b}$ \\ ${ }^{a}$ Instituto de Física, Universidade de São Paulo, CP 66318, 05315-970 São Paulo-SP, Brazil \\ ${ }^{b}$ Instituto Nacional de Pesquisas Espaciais, 12227-010 São José dos Campos-SP, Brazil
}

\begin{abstract}
Filmes de nitreto de carbono, preparados por deposição assistida por feixe de íons, foram estudados pela espectroscopia de Raman e infravermelho, em função de energia de íons (200, 400 , e $600 \mathrm{eV}$ ) e razão de chegada de íon a átomo $\mathrm{R}(\mathrm{I} / \mathrm{A})$ de 0,9 a 2,5. A razão de composição N/C no filme, determinada por análise de detecção de recuo elástico, foi encontrada proporcional a $\mathrm{R}(\mathrm{I} / \mathrm{A})$; porém, a formação de filme é possível somente se $\mathrm{R}(\mathrm{I} / \mathrm{A})$ for menor do que um valor crítico da eficiência de "sputtering" químico. Esse valor encontrado foi de 0,21. O valor máximo de N/C obtido foi de 0,9 (47\% atômica de nitrogênio) para o filme depositado com 400 eV. Para entender o efeito de incorporação de nitrogênio na estrutura dos filmes, os parâmetros foram determinados pela análise dos espectros Raman e encontrados fortes dependências da quantidade de nitrogênio nos filmes; os comportamentos da posição e da largura do pico G, e da razão $\mathrm{I}_{\mathrm{D}} / \mathrm{I}_{\mathrm{G}}$ são correlacionados com as mudanças estruturais nos filmes.
\end{abstract}

Carbon nitride films prepared by ion beam assisted deposition were studied by Raman and infrared spectroscopy, as a function of nitrogen ion energy $(200,400$, and $600 \mathrm{eV})$ and the ion to atom arrival rate ratio $\mathrm{R}(\mathrm{I} / \mathrm{A})$ ranging from 0.9 to 2.5 . The composition ratio N/C in the film determined by elastic recoil detection analysis was found to be proportional to $\mathrm{R}(\mathrm{I} / \mathrm{A})$; however, the film growth is possible only if $\mathrm{R}(\mathrm{I} / \mathrm{A})$ is smaller than a critical value of chemical sputtering yield. This value was found to be 0.21 . The maximum value of N/C obtained was 0.9 (47 at.\% of nitrogen) for the film deposited with ion energy of $400 \mathrm{eV}$. In order to understand the effect of nitrogen incorporation on the structure of the films, the parameters were determined from the Raman spectra analysis of the films and found to show strong dependences of the nitrogen content in the films; the behaviors of the $\mathrm{G}$ peak position and width, and $\mathrm{I}_{\mathrm{D}} / \mathrm{I}_{\mathrm{G}}$ ratio are correlated with the structure changes in the films.

Keywords: carbon nitride, Raman spectroscopy, infrared spectroscopy, ion beam deposition.

\section{Introduction}

Liu and Cohen's theoretical work in 1989 indicated that $\beta-\mathrm{C}_{3} \mathrm{~N}_{4}$ analogous to $\beta-\mathrm{Si}_{3} \mathrm{~N}_{4}$ should be reasonably stable and that its hardness might be equal or superior to that of diamond. ${ }^{1}$ In the structure of this hypothetical material, each $\mathrm{sp}^{3}$-hybridized carbon atom is nearly tetrahedrally surrounded by four $\mathrm{sp}^{2}$-hybridized nitrogen atoms and each nitrogen triply coordinated with three carbon atoms as the nearest neighbors occupies in a trigonal plane site.

Several techniques have been employed to deposit this material, such as reactive magnetron sputtering, ${ }^{2,3} \mathrm{RF}$

\footnotetext{
*e-mail: wilmer.alexe@dfn.if.usp.br
}

reactive ${ }^{2-5}$ and DC magnetron sputtering, ${ }^{2,3}$ and dual ion beam deposition. ${ }^{6-10}$ The ion beam assisted deposition (IBAD) technique is vacuum deposition of material onto a substrate combined with simultaneous ion irradiation. ${ }^{3,7}$ The flux and the energy of incident ions can be changed independently of the flux of depositing atoms, thereby easily controlling the chemical composition of compound films. The materials prepared with these techniques were amorphous, indicating sometimes the presence of microcrystallites of carbon nitride. According to Matsumoto et al., ${ }^{11}$ the comparison of experimental X-ray and electron diffraction patterns assigned to crystalline carbon nitride with simulated ones leads us to conclude that no evidence for the existence of $\mathrm{C}_{3} \mathrm{~N}_{4}$ with the predicted structures has ever been presented in the literature so far. It is known that 
the nitrogen concentration in carbon nitride films has not been found to exceed a value of $\mathrm{N} / \mathrm{C}=0.83$ $(\sim 45$ at. $\%) ;^{3}$ however, films prepared by the IBAD technique showed high nitrogen incorporation $(\mathrm{N} / \mathrm{C}=1.4-1.7){ }^{12}$

The present study reports the preparation of carbon nitride films on a Si (100) substrate by electron-beam evaporation of carbon with simultaneous bombardment by nitrogen ions, as a function of two process parameters: the ion energy and the ion-to-atom arrival rate ratio, $\mathrm{R}(\mathrm{I} / \mathrm{A})$. The $\mathrm{R}(\mathrm{I} / \mathrm{A})$ is defined as the ratio of the flux of incident ions in the ion beam relative to the flux of the evaporated carbon atoms transported to the substrate. The purpose of this study is to relate the lattice dynamics and the chemical composition of the films, which were investigated by means of Raman and Fourier transform infrared (IR) spectroscopy, and by elastic recoil detection analysis (ERDA), respectively, to the two process parameters.

\section{Experimental}

The IBAD system consists fundamentally of a Kaufman-type ion source (Ion Tech Inc.), an electronbeam evaporator and a quartz crystal monitor in a vacuum chamber evacuated by a cryo-pump and a turbo-molecular pump assisted by a mechanical pump. The base pressure in the vacuum chamber was below $4.6 \times 10^{-4} \mathrm{~Pa}$. $99.999 \%$ pure graphite was evaporated by the electron-beam evaporator and the carbon vapor was deposited on a chemically cleaned Si (100) substrate maintained at $350{ }^{\circ} \mathrm{C}$. The incident angle of the flow of evaporated carbon atoms was $45^{\circ}$ and the deposition rate of carbon measured by the quartz crystal monitor was kept at 0.045 $\mathrm{nm} \mathrm{s}{ }^{-1}$. During the deposition of the film, the substrate surface was perpendicularly exposed to the nitrogen ion beam from the ion source. The ion energy was 200, 400 or $600 \mathrm{eV}$. The working pressure in the vacuum chamber was kept at $1.6 \times 10^{-2} \mathrm{~Pa}$.

The $\mathrm{R}(\mathrm{I} / \mathrm{A})$ was calculated using the deposition rate of carbon atoms and the ion beam current density passed through a Faraday cup placed at the position of the substrate. Since a mass analyzer was not available for the vacuum chamber, the charge state distribution of ions was assumed to be $11 \% \mathrm{~N}^{+}$and $89 \% \mathrm{~N}_{2}^{+}$using the published data. ${ }^{13,14}$ A part of these ions is expected to undergo charge transfer collisions with neutral nitrogen gas along the beam trajectory of $41 \mathrm{~cm}$ from the exit of the ion source to the substrate, thus becoming neutral particles retaining the initial energy. Consequently, it was necessary to correct the beam current, as measured with an amperimeter, with the following generic equation $I=I_{\mathrm{o}} \exp \left(-3.54 \times 10^{16}\right.$ $p \sigma l),{ }^{15,16}$ where $I_{\mathrm{o}}$ is the initial current of ions at the exit of the ion source, $I$ the final current at the position of the substrate after passing through the distance $l(\mathrm{~cm})$ of nitrogen gas at pressure $p$ (Torr), and $\sigma\left(\mathrm{cm}^{2}\right)$ the chargetransfer cross section, which is given in Reference 15, dependent on ion species and energy. Variation of R(I/A) was achieved by varying the ion beam current of nitrogen.

Film thickness was determined with a surface profilometer (Sloan, Dektak 3030) and with X-ray reflectivity (XRR) measurements using an X-ray diffractometer (Rigaku, Rint 2100). The composition ratio N/C of the film was determined by the ERDA technique with $58 \mathrm{MeV} \mathrm{Cl}^{7+}$ ions impinging at an angle of $30^{\circ}$ relative to the film surface. IR and Raman spectra were measured ex situ in a dry nitrogen gas atmosphere and at room temperature using a spectrometer (BIO-RAD, FTS-40) and another (Renishaw, Raman 2000) operating with an $\mathrm{Ar}^{+}$ laser excitation line of $514.5 \mathrm{~nm}$, respectively.

\section{Results and Discussion}

Figure 1 shows the deposition rate of the film obtained from the film thickness which was measured with the surface profilometer, divided by the deposition time for the film. This deposition rate decreases with increasing in $\mathrm{R}(\mathrm{I} / \mathrm{A})$ for the three ion energies and a similar feature is observed for the results obtained using the XRR. Note in the figure that: $(i)$ the experimental point at $\mathrm{R}(\mathrm{I} / \mathrm{A})=0$ is for the film prepared without any ion irradiation and (ii) the thickness of the film prepared at $400 \mathrm{eV}$ with $\mathrm{R}(\mathrm{I} / \mathrm{A})=$ 2.5 was not detected in the surface profilometer nor XRR measurements. The Raman spectrum for this film observed, but its ERDA signal was too small to analyze.

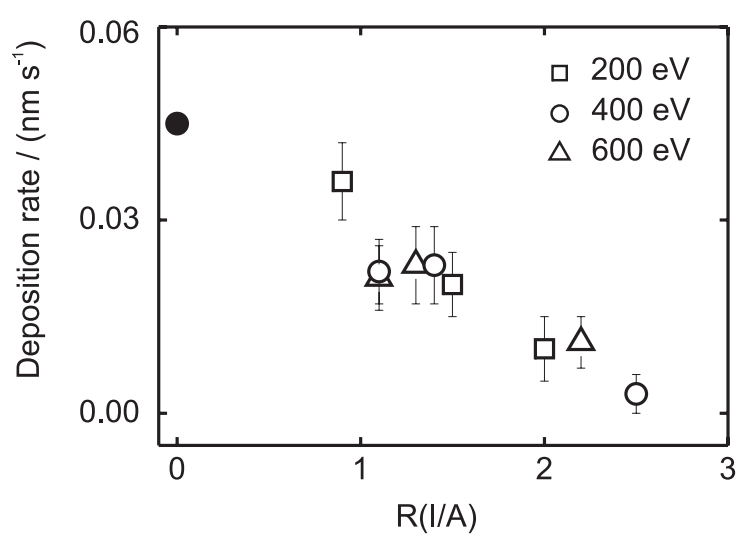

Figure 1. Deposition rate of the films as a function of R(I/A).

Incident ions penetrate into the film and cause collision cascades of recoils by displacing bonded atoms of the film. These incident ions generally accumulate in a surface layer and can form volatile compounds with surface layer atoms. The formation of these compounds lower the 
surface binding energy and they can be desorbed from the surface (chemical sputtering). Hammer and Baker ${ }^{6}$ observed with a quadrupole gas analyzer the production of volatile compounds, such as $\mathrm{CN}^{+}, \mathrm{HCN}^{+}, \mathrm{C}_{2} \mathrm{~N}_{2}^{+}$, during the deposition process of carbon nitride films at 100 and $400{ }^{\circ} \mathrm{C}$ by the dual ion beam deposition technique with assisting nitrogen ion energies between 100-800 eV. ${ }^{6}$ Assuming that physical sputter is negligible owing to low ion energies, they estimated that the chemical sputtering yield $\mathrm{Y}(\mathrm{C} / \mathrm{N})$, defined by the ratio of the number of sputtered carbon atoms to that of incident atomic nitrogen in the ion beam, is equal to $0.25 \pm 0.05 .^{6,8}$ The higher the $\mathrm{R}(\mathrm{I} / \mathrm{A})$, the stronger the formation rate of volatile $\mathrm{CN}$ compounds and, consequently, the film formation ceases. The data shown in Figure 1 are not yet adequate for investigation of the ion energy dependence of $\mathrm{Y}(\mathrm{C} / \mathrm{N})$, and hence a mean critical value of $\mathrm{R}(\mathrm{I} / \mathrm{A})$ at which the film formation begins to cease can be estimated to be equal to 0.21 in our case. The value estimated in this study for the $\mathrm{Y}(\mathrm{C} / \mathrm{N})$ is in line with that obtained by Hammer and Gissler, ${ }^{8}$ implying that the contribution of physical sputtering is small.

The composition ratio N/C in the film is depicted in Figure 2 as a function of R(I/A). From the figure N/C increase with the increase in $\mathrm{R}(\mathrm{I} / \mathrm{A})$ for the three values of ion energy. The highest value of $\mathrm{N} / \mathrm{C}=0.9$ (i.e. 47 at.\% of nitrogen) was observed at $\mathrm{R}(\mathrm{I} / \mathrm{A})=1.4$. It is observed from the figure that the films deposited with $400 \mathrm{eV}$ always show the highest values of N/C in the films for a given value of $\mathrm{R}(\mathrm{I} / \mathrm{A})$. A similar result was shown by Hammer and Baker ${ }^{6}$ without any their comment, that is, the nitrogen concentration for the films deposited at 100 ${ }^{\circ} \mathrm{C}$ with $300 \mathrm{eV}$ was twice higher than that for the films deposited at $100{ }^{\circ} \mathrm{C}$ with $800 \mathrm{eV}$ for a given value of $\mathrm{R}(\mathrm{I} / \mathrm{A})$. We suspect that chemical reactions between

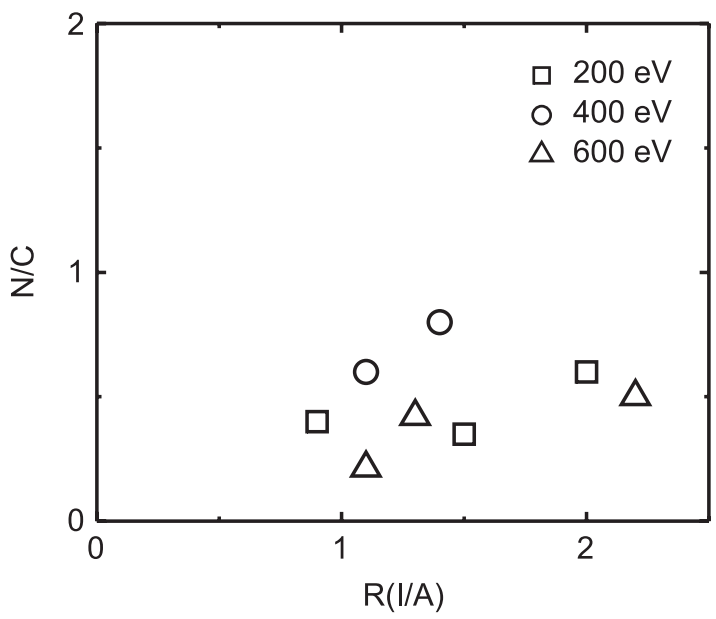

Figure 2. Composition ratio N/C versus R(I/A). physisorbed, chemisorbed, and backscattering species on the surface, which can lead to the formation of volatile compounds, should be dependent on ion energy. Note that the nitrogen concentration ranges for the films deposited with 200,400 , and $600 \mathrm{eV}$ in this study are found to be 28-40, 17-37, and 37-47 at.\%, respectively.

Figures 3 and 4 show the evolution of IR absorption spectra for the films prepared with 400 and $600 \mathrm{eV}$, respectively. There are five prominent features in the spectra: a broad band around $1000-1700 \mathrm{~cm}^{-1}$, two small peaks at 2180 and $2360 \mathrm{~cm}^{-1}$, overlapping peaks around $2700-3000 \mathrm{~cm}^{-1}$, and small band at $3200-3600 \mathrm{~cm}^{-1}$. It is known that all the features in the $1000-1700 \mathrm{~cm}^{-1}$ region in carbon samples are due to skeletal $\mathrm{C}=\mathrm{C}$ vibrations and this suggests that the $1000-1700 \mathrm{~cm}^{-1}$ band in this study is attributed to $\mathrm{C}=\mathrm{C}$ modes or mixed $\mathrm{C}=\mathrm{N}$ modes. ${ }^{2,9}$ Regarding the $2180 \mathrm{~cm}^{-1}$ peak there is no doubt about the origin of this peak to $\mathrm{C} \equiv \mathrm{N}$ modes, which was confirmed by ${ }^{15} \mathrm{~N}-{ }^{14} \mathrm{~N}$ isotopic substitution, ${ }^{9,17}$ and the $2360 \mathrm{~cm}^{-1}$ doublet peak is attributed to environmental $\mathrm{CO}_{2}$ gas. ${ }^{18}$ Two principal peaks at $2850 \mathrm{~cm}^{-1}$ and $2920 \mathrm{~cm}^{-1}$ in the overlapping peaks are due to $\mathrm{sp}^{3} \mathrm{CH}_{2}$ (asymmetric), and $\mathrm{sp}^{3} \mathrm{CH}$ and $\mathrm{sp}^{3} \mathrm{CH}_{2}$ (symmetric) vibrations, respectively, and a very small peak observed at $2950 \mathrm{~cm}^{-1}$, to olefinic $\mathrm{sp}^{2} \mathrm{CH}_{2}$ vibrations. ${ }^{4,18,19}$ Alvarez et al.$^{10}$ observed a peak at $3362 \mathrm{~cm}^{-1}$ in the $3200-3600 \mathrm{~cm}^{-1}$ region and attributed it to stretching modes of $\mathrm{N}-\mathrm{H}$ bonds in $\mathrm{NH}$ and $\mathrm{NH}_{2}$ configurations and to hydroxyl group $\mathrm{OH}$ which can be incorporated after exposing the films to air. The presence of the $\mathrm{CH}_{x}$ band and the $\mathrm{N}-\mathrm{H}$ and $\mathrm{OH}$ band means the contamination of hydrogen and oxygen in the films, no clear dependence on the ion energy and R(I/A) being

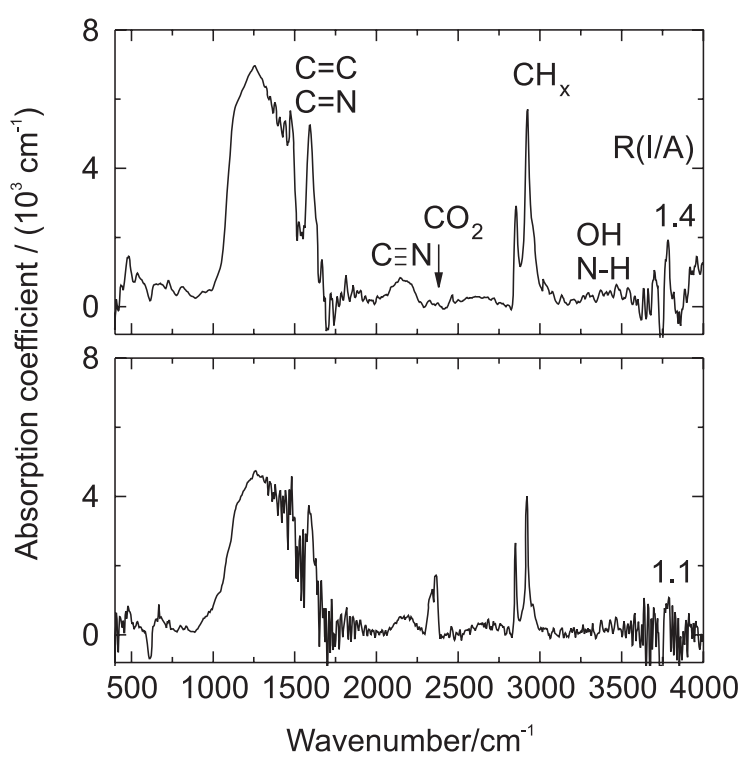

Figure 3. IR spectra of the films prepared with $400 \mathrm{eV}$. 


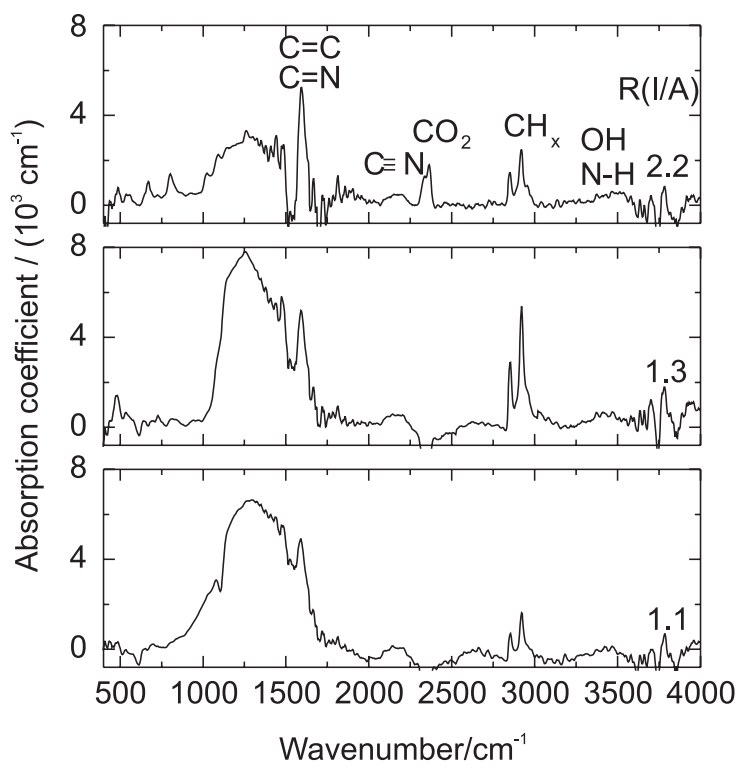

Figure 4. IR spectra of the films prepared with $600 \mathrm{eV}$.

observed. The origin of these elements should be residual gases in the vacuum chamber and/or atmospheric moisture due to the post-deposition exposure of the films to air. Unfortunately, it was impossible to detect hydrogen using our ERDA measurement setup and no oxygen signal was observed within the ERDA detection sensitivity.

The most obvious feature in our IR spectra is a peak at $1590 \mathrm{~cm}^{-1}$ which is well separated from the broad band at lower wavenumbers. This sharp and intense peak, which has been exclusively observed in hydrogenated films, ${ }^{9}$ grows monotonously with increasing R(I/A), almost twice as the broad band, in contrast with spectra observed by Victoria et al..${ }^{9}$ in hydrogenated films. However, ${ }^{15} \mathrm{~N}-{ }^{14} \mathrm{~N}$ or H-D substitution showed that there are not significant shifts of wavenumber expected for the $1000-1700 \mathrm{~cm}^{-1}$ band if specific $\mathrm{N}$-related or $\mathrm{H}$-related modes were involved. ${ }^{2,9,17}$ The consensus is that the $1000-1700 \mathrm{~cm}^{-1}$ band is not predominantly due to nitrogen-containing modes. The increase of the $1590 \mathrm{~cm}^{-1}$ peak in intensity with increasing $R(I / A)$ can be attributed to the presence of the nitrogen causing other vibration modes to be IR active. ${ }^{2,9,17}$

Figure 5 shows normalized Raman spectra for the films deposited with $200 \mathrm{eV}$. Four characteristic features are observed in the spectra: a small band near $700 \mathrm{~cm}^{-1}$, a square-topped band at $980 \mathrm{~cm}^{-1}$ due to $\mathrm{Si}-\mathrm{Si}$ vibrations of the underlying Si substrate, a broad and dominant band in the region of 900-2000 $\mathrm{cm}^{-1}$, and a weak one near 2220 $\mathrm{cm}^{-1}$ assigned to $\mathrm{sp}^{1}$-bonded $\mathrm{C} \equiv \mathrm{N}$ configurations which are expected for terminator groups. The assignment of the $700 \mathrm{~cm}^{-1}$ band is controversial. It is assigned sometimes to $\mathrm{sp}^{3}$-carbon-related vibration, ${ }^{5}$ in-plane-rotation of sixfold aromatic rings in graphite planes, ${ }^{19}$ or transverse optic phonon induced by curvature of the graphitic planes in the nanoparticles (similar to carbon nano-onions)..$^{20}$ This point will be discussed later.

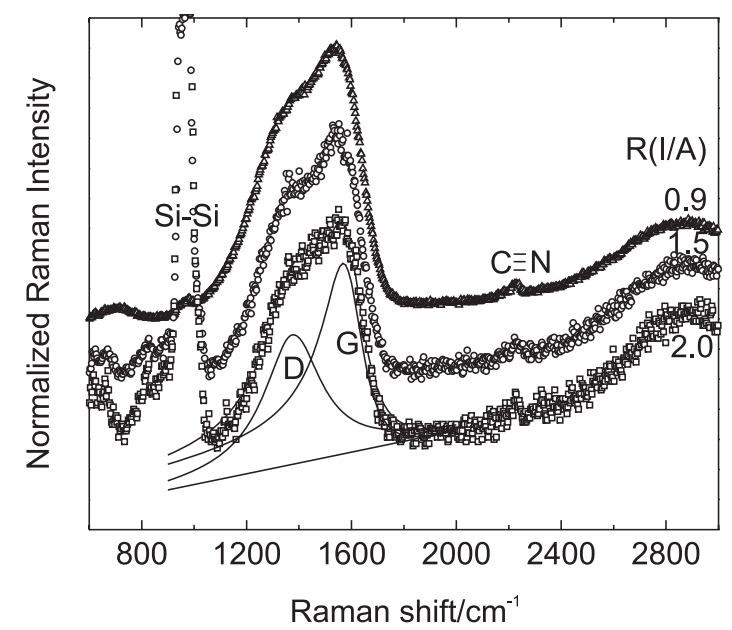

Figure 5. Normalized Raman spectra of the films prepared with $200 \mathrm{eV}$.

The $900-2000 \mathrm{~cm}^{-1}$ band is decomposed into two peaks, G and D peaks. ${ }^{2,7,19-21}$ The G peak located at $1500-1600$ $\mathrm{cm}^{-1}$ originates from stretching vibrations $\left(\mathrm{E}_{2 \mathrm{~g}}\right.$ symmetry) of any pair of $\mathrm{sp}^{2}$ sites in aromatic rings or olefinic chains. The $\mathrm{D}$ peak near $1350 \mathrm{~cm}^{-1}$ arises from the breathing mode $\left(\mathrm{A}_{\mathrm{lg}}\right.$ symmetry) of $\mathrm{sp}^{2}$ sites in clusters of six-fold aromatic rings. ${ }^{2,719-22}$ The $\mathrm{D}$ peak intensity is quite sensitive to the cluster size and, as the cluster size increases, this intensity decreases with respect to that of the G peak. The spectra were analyzed by fitting a Breit-Wigner-Fano (BWF) function to the $G$ peak and a Lorentzian to the D peak to estimate the peak parameters using a linear least-squares computer program, as showed in Figure 5. This fitting method has been widely used for quantitative analyses for the D and G peaks in the carbon structures. The BWF function is described by the following expression: ${ }^{7,19}$

$I(k)=\frac{I_{0}\left[1+2\left(k-k_{0}\right) / q \Gamma\right]^{2}}{1+\left[2\left(k-k_{0}\right) / \Gamma\right]^{2}}$

with the maximum positioned given by

$k_{\max }=k_{0}+\Gamma / 2 q$

where $I(k)$ is the intensity as a function of wavenumber $k$, $I_{0}$ is the peak intensity, $k_{0}, k_{\max }$ and $\Gamma$ are the mean peak position, the peak position at the maximum, and the full width at half maximum, respectively, and $q$ is the BWF coupling coefficient. The position of the $G$ peak is defined 
by $k_{\max }$ and, in the limit $q^{-1} \rightarrow 0$, the lorentzian function is reproduced.

The peak parameters obtained such as the $G$ peak position, the $G$ peak width $\Gamma$, and the intensity ratio of the $D$ to $G$ peak $I_{D} / I_{G}$ are shown as function of $R(I / A)$ in Figures 6(a)-6(c), respectively.

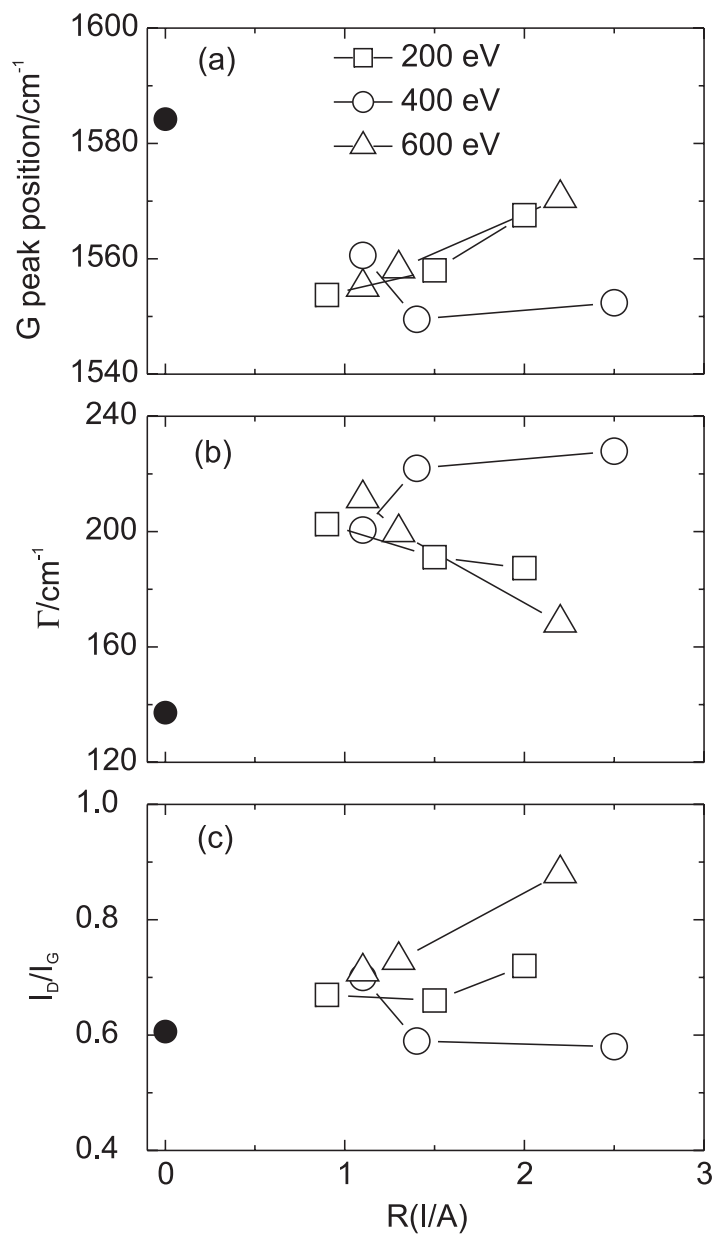

Figure 6. G peak position (a), width $\mathrm{G}$ peak $\Gamma$ (b), and $\mathrm{I}_{\mathrm{D}} / \mathrm{I}_{\mathrm{G}}$ versus $\mathrm{R}(\mathrm{I} / \mathrm{A})$ (c). The solid lines are guides for the eyes.

The films in this study were prepared from graphite evaporation. In order to explain our Raman spectra, we therefore use a phenomenological model relating the peak parameters to three stages of disordered carbon. ${ }^{2}$ The three stages are as follows: $(i)$ perfect graphite to nanocrystalline graphite; (ii) nanocrystalline graphite to $\mathrm{sp}^{2}$ amorphous carbon ( $a-\mathrm{C})$; (iii) $\mathrm{sp}^{2} a-\mathrm{C}$ to tetrahedral $\mathrm{sp}^{3}$ amorphous carbon ( $t a-\mathrm{C}$, or diamond). Stage 1 corresponds to the progressive reduction in cluster size of ordered graphite layers, while keeping aromatic ring, and stage 2, to the disordering of graphite layers and loss of aromatic bonding, but keeping a purely $\mathrm{sp}^{2}$ network. In stage 3 , the $\mathrm{sp}^{3}$ content increases from zero to $100 \%$, accompanying the $\mathrm{sp}^{2}$ configuration change from mainly rings to short chains.

On the other hand, nitrogen incorporation into a carbon network has the following effects on the aromatic clustering kinetics: ${ }^{7}(i)$ nitrogen incorporation changes the bonding length compared with the pure carbon network; (ii) nitrogen enhances the ordering process in a highly disordered carbon network; (iii) nitrogen incorporation into the hexagonal aromatic ring induces corrugating or buckling the basal plane of the graphite with pentagonal rings (fullerene-like structure), promoting cross-linking between adjacent planes through $\mathrm{sp}^{3}$ carbon; ${ }^{23}(i v)$ nitrogen acts as the terminating configuration and hinders the cluster growth.

According to the three-stage model, the film grown without any ion irradiation and all the films deposited with ion irradiation in the present study are considered, from the values of the $G$ peak position and $I_{D} / I_{G}$ ratio, to be at stage $i$ and stage $i i$, respectively. On passing from stage $i$ to $i i$, the disorder and aromaticity loss weakens the bonds through effect $i$ above mentioned, causing the $\mathrm{G}$ peak to shift downward, and a larger variety of $\mathrm{sp}^{2}$ bond length and angle distortions broadens the $\mathrm{G}$ peak. ${ }^{2,7,18,19,24}$ These explain the differences in vertical position between the film grown without irradiation and the others in Figures 6(a) and 6(b).

With increasing nitrogen incorporation into the films in stage $i i$, two completely different behaviors of the peak parameters can be seen in Figures 6(a)-6(c). The G peak for the films deposited with 200 and $600 \mathrm{eV}$ shifts toward higher wavenumbers as $\mathrm{R}(\mathrm{I} / \mathrm{A})$ increases, while that for the films grown with $400 \mathrm{eV}$ moves down in energy and then slightly move up. Opposite behaviors on the variation of $\Gamma$ can be identified. The $I_{D} / I_{G}$ ratio for the films deposited with 200 and $600 \mathrm{eV}$ has a tendency to increase and that for the films with $400 \mathrm{eV}$ has a tendency to decrease.

The increase of the $G$ peak position and the decrease of $\Gamma$ observed for the films deposited with 200 and 600 $\mathrm{eV}$ as $\mathrm{R}(\mathrm{I} / \mathrm{A})$ increases are attributed to the enhancement of the ordering process from amorphous carbon to nanocrystalline graphite (effect ii), i.e., the development of the clustering of the graphitic $\mathrm{sp}^{2}$ phase, followed by an increase in the aromatic cluster size (i.e., an increase in $\left.\mathrm{I}_{\mathrm{D}} / \mathrm{I}_{\mathrm{G}}\right) .{ }^{18,24}$ This means that no consideration of effect $i v$ is necessary in this case. A similar behavior was observed by Abrasonis and Gago. ${ }^{7}$

In contrast the downshifts of the $G$ peak position and $\mathrm{I}_{\mathrm{D}} / \mathrm{I}_{\mathrm{G}}$ ratio, and the increase of $\Gamma$ for the films deposited with $400 \mathrm{eV}$ with increasing $\mathrm{R}(\mathrm{I} / \mathrm{A})$ may be related with higher nitrogen content in the films. It is known that further 
nitrogen incorporation in the films enhances $\mathrm{sp}^{3}$ characteristic in the carbon bonds due to the nitrogeninduced formation of pentagonal rings (effect iii). Roy et $a l{ }^{20}$ attributed these two downshifts to this.

Effect iii is known to depend on the nitrogen content and deposition temperature. Hellgren et al. ${ }^{25}$ described three distinct phases in which three different structures are formed according to the nitrogen content and deposition temperature: an amorphous phase is formed below $150{ }^{\circ} \mathrm{C}$ and, above $200{ }^{\circ} \mathrm{C}$, graphite-like and fullerene-like phases are formed; the transition from the graphite-like to the fullerene-like phase is observed at transition concentration of nitrogen ranging from 5 to 15 at.\%. Moreover, Santos and Alvarez ${ }^{26}$ revealed theoretically that: the clusters are planar up to 17 at. $\%$ of nitrogen; above this concentration buckling develops in the clusters and some of the nitrogen atoms relax to positions at $\sim 0.07 \mathrm{~nm}$ above and below the basic plane. This fact explains the decrease of the $G$ peak position and the increase of $\Gamma$. Consequently, the dependence of the peak parameters on $\mathrm{R}(\mathrm{I} / \mathrm{A})$ can be reasonably explained, when the films grown with 200 and $600 \mathrm{eV}$ (28-40 and $17-37$ at.\% of nitrogen, respectively) and those with 400 $\mathrm{eV}(37-47$ at.\%) are in the graphite-like and fullerenelike phases, respectively, in accordance of the phase diagram above mentioned with the transition concentration of $\sim 40$ at. $\%$.

We consider here the possibility of the hydrogen contribution to the downshift of the $G$ peak position. A higher $\mathrm{sp}^{3}$ content in hydrogenated $\mathrm{sp}^{2} a$-C is known to be achieved mainly by hydrogen saturating $\mathrm{C}=\mathrm{C}$ bonds as $\mathrm{CH}_{x}$ groups, rather than by increasing the fraction of $\mathrm{C}-\mathrm{C}$ bonds, as this $a$-C spreads from stage ii to iii. Thus, most $\mathrm{sp}^{3}$ sites are bonded to hydrogen, causing a downshift of the $\mathrm{G}$ peak position and reducing the $\mathrm{sp}^{2}$ cluster size. However, we discard this possibility because the 2700 $3000 \mathrm{~cm}^{-1}$ peaks due to $\mathrm{C}-\mathrm{H}$ stretching modes in carbon $\mathrm{sp}^{2}$ and $\mathrm{sp}^{3}$ configurations appears in similar intensity for the film deposited with $400 \mathrm{eV}$ and $\mathrm{R}(\mathrm{I} / \mathrm{A})=1.4$ and the films grown with $600 \mathrm{eV}$ and $\mathrm{R}(\mathrm{I} / \mathrm{A})=1.3$ (see Figure 3 and 4).

Finally, the assignment of the IR band in the range 1000$1700 \mathrm{~cm}^{-1}$ has been widely discussed, because of the appearance similar between IR and Raman spectra. Some authors consider that nitrogen incorporation into the films causes the Raman $G$ and $D$ peaks to become IR active, due to the symmetry distortion of the $\mathrm{sp}^{2}$ ring modes giving rise to a net dipole moment. ${ }^{17}$ On the contrary, some claim that the two spectra differ. ${ }^{2,9}$ Figure 7 compares the normalized Raman and IR spectra observed for the films deposited with $200 \mathrm{eV}$, in which the $\mathrm{D}$ and $\mathrm{G}$ peaks and the corresponding region of the IR spectra are fitted. We can conclude from the figure that the IR and Raman spectra are not equivalent because of the lack of coincidence between the two. On the other hand, the $700 \mathrm{~cm}^{-1}$ Raman band appears unambiguously for the films grown with 200 and $600 \mathrm{eV}$ as $\mathrm{R}(\mathrm{I} / \mathrm{A})$ decreases (i.e. the intensity of the $\mathrm{D}$ peak increases), supporting its identification as the in-planerotation of six-fold aromatic rings in graphite planes.

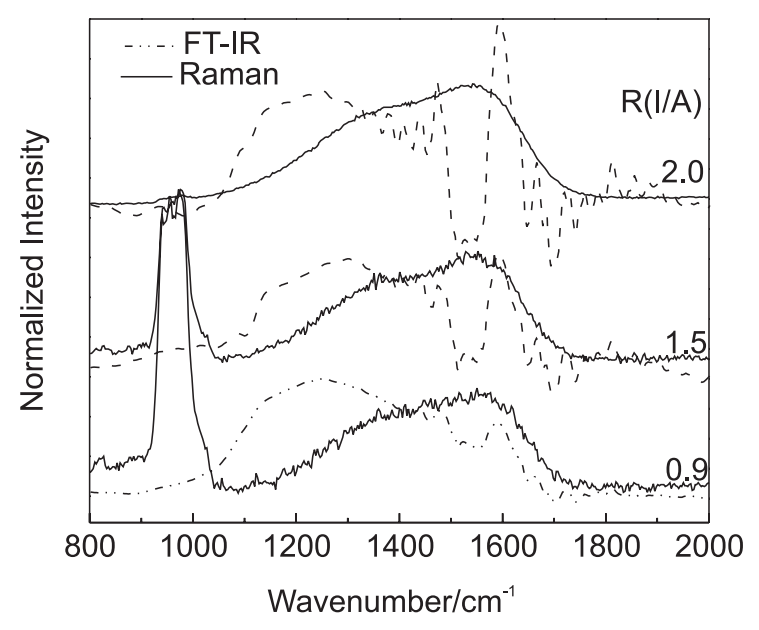

Figure 7. Normalized Raman and IR spectra prepared with $200 \mathrm{eV}$.

\section{Conclusions}

The composition ratio N/C in the films was nearly proportional to $\mathrm{R}(\mathrm{I} / \mathrm{A})$; however, the film growth is possible only if $R(I / A)$ is smaller than a critical value of chemical sputtering yield. This mean value was estimated to be 0.21 which agreed very closely with the value early reported. The films deposited with $400 \mathrm{eV}$ were found to show always the highest values of nitrogen content in the films for a given value of $\mathrm{R}(\mathrm{I} / \mathrm{A})$ and the nitrogen content in our films reached a maximum of 47 at. $\%$. This fact can imply that chemical sputtering may be dependent on ion energy.

The $\mathrm{G}$ peak position, $\mathrm{G}$ peak width, and $\mathrm{I}_{\mathrm{D}} / \mathrm{I}_{\mathrm{G}}$ ratio determined from the analysis of the Raman spectra for the films showed two different behaviors dependent on the nitrogen content. This difference could be explained in the context of the structure phase of the films as follows. Below 40 at.\% of the nitrogen content the films were in the graphitic phase and showed the development of the clustering of the graphitic $\mathrm{sp}^{2}$ phase as the nitrogen content increases. On the other hand, increasing the nitrogen content $\mathrm{e} \geq 40$ at.\% leads to the fullerene-like phase with corrugated and buckled basal planes, promoting crosslinking between adjacent planes through $\mathrm{sp}^{3}$ carbon.

From the analysis of the IR spectra we believe few contribution of hydrogen to the behaviors of the peak 
parameters. The $700 \mathrm{~cm}^{-1}$ Raman band was found to be identified as the in-plane rotation of six-fold aromatic rings in graphite planes and comparison of the Raman and IR spectra allowed us to consider that the both are not equivalent.

\section{Acknowledgments}

The authors would like to acknowledge the helpful assistance of Dr. Manuel Espinoza, Instituto de Física, Universidade de São Paulo, and Dr. Nelson Ordenez, Escola Politécnica, Universidade São Paulo. We are grateful to Fundação de Amparo à Pesquisa do Estado de São Paulo (FAPESP) and Coordenação de Aperfeiçoamento de Pessoal de Nível Superior (CAPES) for the financial support and scholarship, respectively.

\section{References}

1. Liu, A. Y.; Cohen, M. L.; Phys. Rev. B: Condens. Matter Mater. Phys. 1990, 41, 10727.

2. Ferrari, A. C.; Rodil, S. E.; Robertson, J.; Phys. Rev. B: Condens. Matter Mater. Phys. 2003, 67, 155306.

3. Muhl, S.; Méndez, J. M.; Diamond Relat. Mater. 1999, 8, 1809.

4. Dischler, B; Bubenzer, A; Koidl, P.; Solid State Commun. 1983, $48,105$.

5. Kumar, S.; Tansley, T. L.; Thin Solid Films 1995, 256, 44.

6. Hammer, P.; Baker, M. A.; Thin Solid Films 1996, 290-291, 107.

7. Abrasonis, G.; Gago, R.; Phys. Rev. B: Condens. Matter Mater. Phys. 2006, 73, 125427.

8. Hammer, P.; Gissler, W.; Diamond Relat. Mater. 1996, 5, 1152.

9. Victoria, N. M.; Hammer, P.; dos Santos, M. C.; Alvarez, F.; Phys. Rev. B: Condens. Matter Mater. Phys. 2000, 61, 1083.

10. Alvarez, F.; Victoria, N. M.; Hammer, P.; Freire, Jr. F. L.; dos Santos, M. C.; Appl. Phys. Lett. 1998, 73, 1065.
11. Matsumoto, S.; Xei, E. Q.; Izumi, F.; Diamond Relat. Mater. 1999, 8, 1175.

12. Chubaci, J. F. D.; Ogata, K.; Fujimoto, F.; Watanabe, S.; Biersack, J. P.; Nucl. Instrum. Methods Phys. Res., Sect B 1996, 116, 452 .

13. Vecthen, D. V.; Hubler, G. K.; Donovan, E. P.; Vacuum 1986, 36,841 .

14. Smidt, F. A.; Int. Mater. Rev. 1990, 35, 58.

15. Brown, S.C.; Basic Data of Plasma Physics, 1966, MIT Press: Cambrige, MA, 1967, p. 67.

16. Matsuoka, M.; Isotani, S.; Mittani, J. C. R.; Chubaci, J. F. C.; Ogata, K.; Kuratani, N.; J. Vac. Sci. Technol., A 2005, 23, 137.

17. Kaufman, J. H.; Metin, S.; Saperstein, D. D.; Phys. Rev. 1989, 39, 13053.

18. McCann, R.; Roy, S. S.; Papakonstantinou, P.; McLaughlin, J. A.; J. Appl. Phys. 2005, 97, Art. No. 073522.

19. Rodil, S. E.; Ferrari, A. C.; Robertson, J.; Milne, W. I.; J. Appl. Phys. 2001, 89, 5425.

20. Roy, D.; Chhowalla, M.; Hellgren, N.; Phys. Rev. B: Condens. Matter Mater. Phys. 2004, 70, Art. No. 035406.

21. Ferrari, A. C.; Robertson, J.; Phys. Rev. B: Condens. Matter Mater. Phys. 2000, 61, 14095.

22. Tuintra, F.; Koenig, J. L.; J. Chem. Phys. 1970, 53, 1126.

23. Sjöström, H.; Stafström, S.; Boman, M.; Sundgren, J. E.; Phys. Rev. 1995, 75, 1336

24. Kleinsorge, B.; Ferrari, A. C.; Robertson, J.; Milne, W. I.; J. Appl. Phys. 2000, 88, 1149.

25. Hellgren, N.; Johansson M. P.; Broitman, E.; Hultman, L.; Sundgren, J.; Phys. Rev. 1999, 59, 5162.

26. Santos, M. C.; Alvarez, F.; Phys. Rev. 1998, 58, 13918.

Received: March 15, 2006 Published on the web: October 5, 2006

FAPESP helped in meeting the publication costs of this article. 